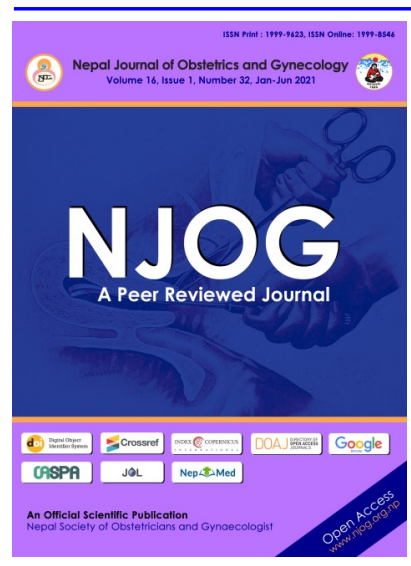

CORRESPONDENCE

Dr Shailaja Khadka

Department of OBGYN, Shree Birendra Hospital, Chhauni, Kathmandu

Email:

drshailajakhaka@gmail. com;

Phone: +977-9841287004

Received: February 4, 2021 Accepted: May 1, 2021

Citation: Khadka S, Khatri R, Malla R, Thapa S Chand A, Acharya I, et al. Prevalence of Anxiety in Pregnancy during COVID 19 pandemic in Shree Birendra Hospital, Chhauni. Nep J Obstet Gynecol. 2021;16(32):16-19. DOI: https://doi.org/10.3126/ njog.v16i1.37507

\title{
Prevalence of Anxiety in Pregnancy during COVID 19 pandemic in Shree Birendra Hospital, Chhauni
}

\author{
Shailaja Khadka, Ratna Khatri, Rosy Malla, Sumana Thapa, Arju Chand, \\ Indira Acharya, Bibhusan Neupane, Sumit Bidari, Kopila Rai, Kanti \\ Prabha Giri, Lokendra Bata \\ Department of OBGYN, Shree Birendra Hospital, Chhauni, Kathmandu
}

\section{ABSTRACT}

Aim: To determine the prevalence of anxiety in pregnancy during COVID19 pandemic in Shree Birendra Hospital, Chhauni

Method: It is a cross sectional study conducted at Shree Birendra Hospital Chhauni from July to October 2020 following the ethical approval from IRC. All the pregnant women from first to last trimester attending outdoor visit were included; they were asked to fill up Beck Anxiety Index form. The level of anxiety was compared with demographic data like age, race, parity, and period of gestation, education and occupation. Data were analyzed by using SPSS 20 software.

Results: A total of 385 presumably uninfected pregnant women were surveyed in $20-40(28.45 \pm 3.95)$ years age group from 4 to $41(27.15 \pm 9.4)$ weeks of pregnancy and $55.6 \%$ were multipara. Low-grade anxiety was found $99.5 \%(\mathrm{BAI}=$ $3.06 \pm 3.66)$.

Conclusions: Low-grade anxiety was found in almost all pregnant women during covid pandemic and there was no significant difference by demographic variables.

Keywords: anxiety, covid, pregnancy

\section{INTRODUCTION}

Pregnancy is a state of partial immune suppression, which makes pregnant women more vulnerable to viral infections, and the morbidity is higher even with seasonal influenza. Therefore, the Coronavirus disease 2019 (COVID-19) pandemic may have serious consequences for pregnant women. COVID-19 has led to the deadliest pandemic observed in more than 100 years. ${ }^{1}$ Albeit all individuals are at a risk of being infected, the susceptible ones include the pregnant women as they are more prone to be affected by the virus. ${ }^{2}$ As of this writing, there are more than 25 million confirmed cases and 9 million deaths worldwide. ${ }^{3}$ Anxiety is a feeling of worry, nervousness, or unease about something with an uncertain outcome and it can co-exist, predispose or cause depression. ${ }^{4}$ Mental health problems are common in pregnancy, typically affecting between 10 and $25 \%$ of pregnant individuals. ${ }^{5}$ Due to limited information, assessment and management of pregnant women infected with COVID-19, rapid increase in number of COVID19 cases certainly results in an increased level of stress and anxiety among pregnant women. ${ }^{6}$ The COVID-19 pandemic has created an urgent need to examine the extent to which pandemic-related stress predicts heightened anxiety in women pregnant during this crisis. ${ }^{7}$ Pregnant women assessed after the declaration of coronavirus disease 2019 epidemic had significantly higher rates of depressive symptoms. ${ }^{8}$ Women are most concerned about older relatives, then their children, followed by their unborn child. ${ }^{9}$ The Beck Anxiety Inventory (BAI) is used to calculate the anxiety symp- 
toms. It comprises of 21 items. $^{10}$

Currently, studies and clinical routines concentrate on the treatment and prevention of COVID-19 to reduce mortality rates, but only few investigations have been devoted to its psychological effects on the general population and health workers. The unpredictability of the pandemic, the effects of consequent restrictions, and the ensuing breeding of fear indicate that any aspect of the COVID-19 pandemic can affect pregnant women. As mentioned above, research on the psychological effects of the pandemic. ${ }^{6}$ Most studies in COVID-19 in pregnancy have focused on physical effects of the pandemic on infected mothers as well as the possibility of vertical transmission. ${ }^{11}$

To fill this void, we inquired into the effects of this crisis on anxiety in pregnant women. Shree Birendra Hospital is an army background hospital, which caters to all the female patients serving soldiers and family of Nepalese Army. The aim of this study was to know the prevalence of anxiety in pregnant women at Shree Birendra Hospital during COVID-19 pandemic.

\section{METHOD}

A cross sectional study was conducted at Shree Birendra Hospital Chhauni from July to October 2020 following the ethical approval from IRC. All pregnant women from first to last trimester attending the OPD of Shree Birendra Hospital were included as cases for the study. Pregnant women in labour and with past history of mental disorder were excluded from the study. The sample size was calculated to be 385 with the unknown prevalence.

Beck Anxiety Index was used as to assess the severity of clinical anxiety. Anxiety related symptoms according to this index includes 21 symptoms. The data collected was scored from 0-3 with minimum of 0 to maximum of 63 . The data was divided into mild, moderate and severe. Patient privacy and confidentiality was maintained. The level of anxiety was compared with demographic data like age, race, parity, period of gestation, education and occupation. First, prevalence of anxiety in the pregnant women anxieties was calculated, t-tests and chisquare tests were conducted to examine differences in background variables between the ethnic groups, parity primiparous and multiparous women, different periods of gestations, educational and occupational status. Finally, Pearson correlation were calculated between the socio demographic variables on the one hand, and the COVID-19-related anxieties.
All collected data was analyzed by using SPSS 20 software.

\section{RESULTS}

A total of 385 individuals were survey between July and October 2020 and were included in current analysis. In the study prevalence of low grade anxiety were found to be $99.5 \%$ and rest had moderate level.

Participants were aged 20 - 40 (28.45 \pm 3.95$)$ years that were in gestational age group of 4-41 (27. 15 \pm 9.40$)$ weeks who were not to the best of our knowledge infected with the virus at the time of the study. The BAI ranges from 0 to 22 (3.06 \pm 3.66$)$ with low anxiety level. There were $214(55.6 \%)$ multipara, $99.5 \%$ literate and 52\% housewife.

Among 385 study population, Hindu by religion were 354 (91.9\%) and 31(8.1\%) Buddhist. By trimester of pregnancy 25, 141 and 194 cases were in first, second and third trimester respectively. There were 214 (55.6\%) multiparous and $171(44.4 \%)$ primiparous with mean BAI 2.75 and 3.44 respectively $(\mathrm{p}=0.071)$. But none of them were significantly different. [Table-1]

Table-1: BAI by demographic attributes

\begin{tabular}{lll}
\hline Parameters & BAI & p-value \\
\hline Housewife/working & $3.12 / 3.00$ & 0.762 \\
Hindu/Buddhist & $3.99 / 2.87$ & 0.207 \\
1st/2nd/3rd Trimester & $3.08 / 2.78 / 1.58$ & 0.194 \\
Multipara/Pripmipara & $2.75 / 3.44$ & 0.071 \\
\hline
\end{tabular}

There was a positive correlation of BAI between age $(\mathrm{r}=0.076, \mathrm{p}=0.138)$ and period of gestation ( $\mathrm{r}=0.041, \mathrm{p}=0.138)$; and a negative correlation between parity $(\mathrm{r}=-0.90, \mathrm{p}=0.079)$ and education $(\mathrm{r}=-0.040, \mathrm{p}=0.429)$. It was not significantly correlated. [Table-2]

Table-2: Pearson's correlation of BAI by age, gestation, parity and education

\begin{tabular}{lcc}
\hline Parameters & $\mathrm{r}$ & $\mathrm{p}$-value \\
\hline Age & +0.076 & 0.138 \\
Gestational age & +0.041 & 0.138 \\
Parity & -0.90 & 0.079 \\
Education status & -0.040 & 0.429 \\
\hline
\end{tabular}




\section{DISCUSSION}

The study reported low level of anxiety according to Beck Anxiety Index, which were $99.5 \%$ and $0.5 \%$ of moderate level of anxiety; there was no cases documentation of severe cases of anxiety. In a survey of C. Wang et al, early in the COVID-19 outbreak in Jan 31-Feb 2, 2020, 17\% of respondents reported moderate or severe depression, and $29 \%$ moderate to severe anxiety. ${ }^{12}$

General anxiety was also elevated compared to a meta-analysis of pregnancy, which reports $18-25 \%$ prevalence and the general US population prevalence of $16 \% .^{13}$ The prevalence of anxiety in pregnant women in turkey has been reported to range from $63 \%$ to $68 \%{ }^{14}$ There were no clinically significant differences seen among the anxiety level in participants in relation to religion, educational or occupational status, parity or period of gestation. Most of the women exhibited low level of anxiety according to BAI.

There is no any significant effect of gestational age on the anxiety levels like in a study done by Mappa et al. ${ }^{13}$ Schubert et al.found that stress scores remained stable throughout pregnancy. ${ }^{15}$ Effanti et $\mathrm{al}^{16}$ also showed no statistically significant relationship between pregnancy trimester stress and anxiety whereas Da Costa et $\mathrm{a}^{17}$ described higher scores during first and third trimester.

In our study there was no significant relationship between anxiety level, parity and age. In the study conducted by mappa et al showed no significant difference in anxiety level between primi parous and multi parous. ${ }^{13}$ Rezaee et al also didn't report a difference in the number of parities and age between anxious and non-anxious women. ${ }^{18}$ While study conducted by Yanting wu et al in china showed increased level of anxiety in primi than in multiparous. ${ }^{19}$ Similarly Dunkel Schetter et al showed a high level of pregnancy anxiety in women during their first delivery. ${ }^{20}$

The anxiety level in both working and housewife were low in our study. Sut HK et al showed the risk of anxiety in pregnant women who were not working was 1.87 times $(95 \%$ confidence interval [CI]: 1.01-3.48] higher than that in pregnant women who were working $(p=.047){ }^{14}$

In our study the women who were literate were $99.4 \%$ and illiterate were $0.6 \%$ but there was no significant difference in the anxiety level between them. Miyake et al reported that there was no rela- tionship between household income or education and the prevalence of depressive symptoms during pregnancy. ${ }^{21}$ But in the study conducted by Sut HK et all showed significant difference The risk of depression in pregnant women whose education level was less than 9 years was 2.76 times higher (95\% CI: $1.22-6.28)$ than that in pregnant women whose education level was 9 years or above ( $p=$ $.015) .{ }^{14}$ Similarly, study conducted by Zhang showed low education levels have been found to be associated with a high prevalence of anxiety and depression in Chinese pregnant women. ${ }^{22}$

\section{CONCLUSIONS}

There is low level anxiety to $99.5 \%$ of pregnant women during Covid pandemic that may reflect the accentuated concerns of pregnant women in the face of the spread of COVID-19. All pregnancy and demographic variables didn't show any significant differences in anxiety level.

\section{REFERENCES}

1. Liang H, Acharya G. Novel corona virus disease (COVID-19) in pregnancy: What clinical recommendations to follow? Acta Obstetricia et Gynecologica Scandinavica. 2020;99(4):439_ 42.

2. Durankuş F, Aksu E. Effects of the COVID-19 pandemic on anxiety and depressive symptoms in pregnant women: a preliminary study. $\mathrm{J}$ Mat Fet Neonat Med. 2020;1(1):1-7.

3. Coronavirus disease (COVID-19) - World Health Organization [Internet]. [cited 2020 Aug 30].

4. Kajdy A, Feduniw S, Ajdacka U, Modzelewski J, Baranowska B, Sys D, et al. Risk factors for anxiety and depression among pregnant women during the COVID-19 pandemic. Medicine (Baltimore) [Internet]. $2020 \mathrm{Jul} 24$ [cited 2020 Aug 30];99(30).

5. Lebel C, MacKinnon A, Bagshawe M, Tomfohr-Madsen L, Giesbrecht G. Elevated depression and anxiety symptoms among pregnant individuals during the COVID-19 pandemic. J Affectiv Dis. 2020;277:5-13.

6. Ali NA, Shahil FA. Maternal mental health amidst the COVID-19 pandemic. Asian J Psychiatr. 2020;54:102261.

7. Preis H, Mahaffey B, Heiselman C, Lobel M. Pandemic-related pregnancy stress and anxiety 
among women pregnant during the coronavirus disease 2019 pandemic. Am J Obstet Gynecol MFM. 2020;2(3):100155.

8. Wu Y, Zhang C, Liu H, Duan C, Li C, Fan J, et al. Perinatal depressive and anxiety symptoms of pregnant women during the coronavirus disease 2019 outbreak in China. Am J Obstet Gynecol. 2020;223(2):240.e1-240.e9.

9. Corbett GA, Milne SJ, Hehir MP, Lindow SW, O'connell MP. Health anxiety and behavioural changes of pregnant women during the COVID19 pandemic. Eur J Obstet Gynecol Reprod Biol. 2020;249:96-7.

10.Beck AT, Epstein N, Brown G, Steer RA. An inventory for measuring clinical anxiety: psychometric properties. J Consult Clinic Psychol. 1988;56(6):893.

11.Kotabagi P, Fortune L, Essien S, Nauta M, Yoong W. Anxiety and depression levels among pregnant women with COVID-19. Acta Obstetricia et Gynecologica Scandinavica. 2020;99 (7):953-4.

12.Wang C, Horby PW, Hayden FG, Gao GF. A novel coronavirus outbreak of global health concern. The Lancet. 2020;395(10223):470-3.

13.Mappa I, Distefano FA, Rizzo G. Effects of coronavirus 19 pandemic on maternal anxiety during pregnancy: a prospectic observational study. J Perinat Med. 2020;48(6):545-50.

14.Sut HK, Kucukkaya B. Anxiety, depression, and related factors in pregnant women during the COVID-19 pandemic in Turkey: A web-based cross-sectional study. Perspect Psych Care. 2020.

15.Schubert KO, Air T, Clark SR, Grzeskowiak LE, Miller E, Dekker GA, et al. Trajectories of anxiety and health related quality of life during pregnancy. PLoS ONE. 2017;12:e181149.
16.Effati-Daryani F, Zarei S, Mohammadi A, Hemmati E, Yngyknd SG, Mirghafourvand M. Depression, stress, anxiety and their predictors in Iranian pregnant women during the outbreak of COVID-19. BMC Psychol. 2020;8(1):1-0.

17.Da Costa D, Larouche J, Dritsa M, Brender W. Variations in stress levels over the course of pregnancy: factors associated with elevated hassles, state anxiety and pregnancy-specific stress. J Psychosom Res. 1999;4:609-21.

18. Rezaee R, Framarzi M. Predictors of mental health during pregnancy. Iranian J Nurs Midwifery Res. 2014;19(7 Suppl1):S45.

19.Wu Y, Zhang C, Liu H, Duan C, Li C, Fan J, et al. Perinatal depressive and anxiety symptoms of pregnant women along with COVID-19 outbreak in China. Am J Obstet Gynecol. 2020;223 (2): 240 .

20.Dunkel Schetter C, Niles AN, Guardino CM, Khaled M, Kramer MS. Demographic, medical, and psychosocial predictors of pregnancy anxiety. Paediatric and perinatal epidemiology. 2016;30(5):421-9.

21.Miyake Y, Tanaka K, Arakawa M. Employment, income, and education and prevalence of depressive symptoms during pregnancy: the Kyushu Okinawa Maternal and Child Health Study. BMC Psychiatr. 2012;12(1):117.

22.Zhang Y, Muyiduli X, Wang S, Jiang W, Wu J, $\mathrm{Li} \mathrm{M}$, et al. Prevalence and relevant factors of anxiety and depression among pregnant women in a cohort study from south-east China. J Reprod Infant Psychol. 2018;36(5):519-29. 